\title{
E-Health: Value Proposition and Technologies Enabling Collaborative Healthcare
}

\author{
Sweta Sneha, PhD \\ ssneha@kennesaw.edu \\ Associate Professor of Information Systems \\ Director of Healthcare Management Informatics \\ Kennesaw State University
}

\author{
Detmar Straub, PhD \\ dstraub@cis.gsu.edu \\ Professor of Computer Information Systems \\ Georgia State University
}

\begin{abstract}
E-health, enabled by ubiquitous computing and communication technologies, is facilitating a fundamental shift in the age old praxis of healthcare. It is revolutionizing healthcare in the $21^{\text {st }}$ century in much the same way as the arrival of modern medicine and vaccines did in the $19^{\text {th }}$ century. E-health lies at the intersection of diverse disciplines including healthcare, computer science, information systems, economics, and political science. The broad impact of E-health on diverse domains, complexity of supporting technologies, and the dizzying interplay of theories bridging multiple disciplines creates a rich problem space for information system researchers and calls on to conduct cross-disciplinary research. In the current paper we present salient characteristics of e-health and discuss its value proposition. The value proposition of e-health presents the entire range of processes supporting the healthcare sector. We also present research opportunities as e-health takes center stage in the delivery of healthcare.
\end{abstract}

\section{Introduction}

Healthcare forms a fundamental constituent of the modern society touching most of us during the course of our lives, accounts for a large percentage of Gross National Product, and sustains a high political profile and strong public interest [32]. A modern healthcare system is a composite structure with complex interactions bounded by strict regulations (Figure 1). It typically consists of the service providers (i.e., doctors, nurses), the consumers (i.e., patients), the insurance companies (payers), pharmaceutical drug providers, diagnostic service providers, and suppliers/vendors.

Over the centuries the praxis of healthcare has evolved and gone through several stages of metamorphosis - from the usage of crude plant extracts to the introduction of modern medicine - before reaching the current stage of maturity. The introduction of vaccines in the 18th century (by Edward Jenner in 1798) led to the eradication of smallpox which had claimed millions of lives. Similarly, the introduction of antibiotics in the first decade of the 20th century (by Paul Ehrlich in 1908) transformed the pattern of diseases and deaths. Many diseases that once challenged human existence - malaria, tuberculosis, pneumonia - now hold lower positions in the mortality table. At each stage of metamorphosis, the praxis of healthcare underwent a fundamental shift that averted the crisis and reduced mortality rates. In the 1800s and 1900s the cornerstone of modern medicine has been novel drug discovery to cure and manage illnesses. Although it is still critical to discovering cure to fatal diseases such as AIDS and cancer however, the turn of the 21st century is posing a threat to the very existence of the healthcare systems around the globe - the challenge is to maintaining wellness instead of managing illness. Healthcare praxis is yet again at the precipitous of change and this time the potential cure might lie in e-health, i.e., healthcare delivery and practice enabled by information, communication, and sensing technologies.

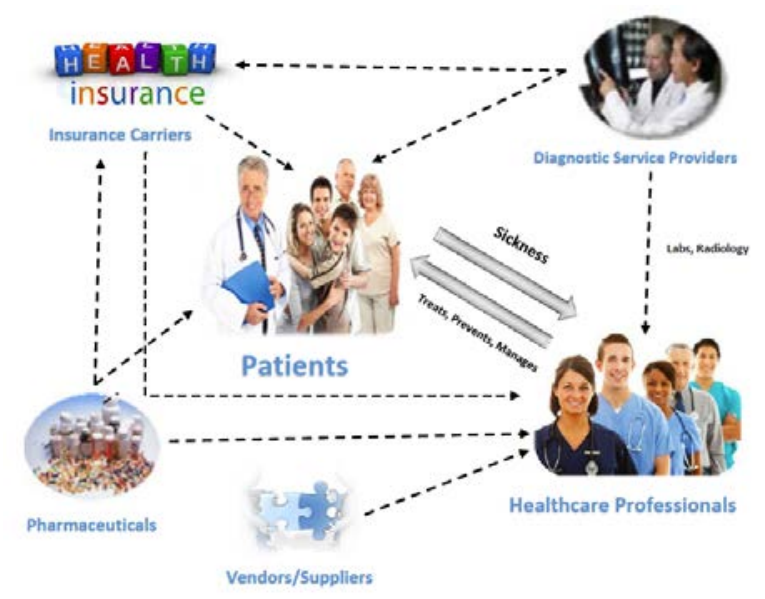

. Figure 1: Key Actors \& Interaction 
At the dawn of the 21st century healthcare systems around the globe are plagued by escalating expenses, exponential increase in the demand/utilization of health services triggered by the graying of the globe, and inadequate financial/human resources to sustain the mounting healthcare needs. Healthcare expenses in US currently represent $15 \%$ of the GNP and the Center for Medicaid and Medicare anticipates the expenses to reach $17 \%$ by the year 2011 [5]. The unprecedented rise in the worldwide aging population - 761 million by 2025 - has witnessed a parallel rise in the prevalence of chronic illnesses. Chronic diseases require long term treatment, continuous monitoring for detection of anomalies, and prompt medical intervention as and when required [34]. The long-term treatment and management of chronic diseases in the aging population results in approximately $78 \%$ of healthcare expenses [32]. Epistemological data suggests that a large percentage of these expenses are a reflection of unsuccessful management of chronic illnesses leading to unnecessary hospitalization at huge expenses to the healthcare sector [31]. The shortage of human resources (doctors and nurses) to meet the increased needs of healthcare services causes the hospitals to hire agency and traveling nurses at huge costs - in 2001, the hospitals spent $\$ 71$ million in meeting nursing needs [1]. The situation is further worsened by the staggering expenses and fatalities associated by lack of adequate information at the point of care leading to errors in disease diagnosis and prescription of drugs. There are approximately 44,000 - 98,000 deaths annually due to medical errors of varying nature including those caused by prescription drug interactions [17]. More than 2 million cases of prescription errors caused by illegible handwriting are reported annually in the United States [17]. Due to cultural problems, such as asking for help, inappropriate experts, referrers too busy and perceived loss of control in developing countries, the demand is not escalating. The healthcare costs associated with treating patients suffering from prescription related errors potentially run into $\$ 17$ billion a year [17]. Administrative inefficiency in the healthcare sector is another key contributor to an increase in health care expenses. Out of the $\$ 1.7$ trillion in healthcare expenses in U.S., $10 \%$ to $12 \%$ was spent exclusively on administrative costs [11].

Given the challenges faced by the healthcare sector (Table 1), a mammoth task faced by healthcare leaders/stakeholders, policy makers, and government is to devise an effective means of providing quality healthcare to an increasing patient population while efficiently managing the limited financial as well as human resources. While traditional praxis of healthcare is crumbling under the weight of escalating costs, increased demand for healthcare services, limited human/financial resources; e-health is evolving in the background. Federal government regulations such as: Healthcare Information Portability and Accountability Act (HIPAA 2003), The Medicare Prescription Drug and Modernization Act of 2003, and HITECH Reform Act of 2009 have not only been instrumental in providing the much needed impetus to e-health but also reflect an effort to leverage technology to increase the quality of healthcare delivery. Although e-health cannot provide a cure to all the terminal maladies faced by the healthcare sector, it can significantly contribute to improvement, if the introduction of e-Health is accompanied by a clear understanding of the underlying healthcare processes [29]. The success is only possible when there is a multi-partnership collaboration between governmental and nongovernmental sectors; the support of academia is also very crucial.

A core component of the Institute of Medicine and the Affordable Care Act of 2011 is patient-centered care, which means patients empowerment with tools and technologies that makes it easier for patients to store, retrieve, and manage their personal health information. Patients are empowered when they have the tools and technologies that support health information management, exchange, and use of personal health information. E-health spans a multitude of disciplines and theories with information system being at the very core of it. The broad impact of Ehealth on diverse domains, complexity of supporting technologies, and the dizzying interplay of theories bridging multiple disciplines creates a rich problem space for information system researchers and calls on to conduct cross-disciplinary research. Yet, there is a dearth of IS research exploring e-health's rich problem space and applying interdisciplinary theories to study and educate the development and maturity of e-health. The objective of the current research is to stimulate interdisciplinary dialogue and research grounded in theory that seeks to investigate a myriad of organizational, technical, behavioral, economic, social, and political opportunities/challenges afforded by the e-health paradigm. The goal of the current research is: 1. To explore the paradigm of e-health in terms of stakeholders, key enabling technologies, requirements/challenges, and its impact

2. To discuss the value proposition of e-health based on the underlying healthcare processes and discuss challenges and research issues.

\section{E-health}

E-Health is a relatively young field of study which lies at the intersection of diverse domains including 
healthcare, computer and information sciences, economics, political science, and business. E-health embodies not only the recent technical advancements in computing, communication, and sensing but also a paradigm shift committed to enhancing the quality and efficiency of healthcare services both locally and globally while reducing the escalating healthcare expenses.

In recent years, buzzwords such as telemedicine, telecare, e-health, telehealth, and m-health, have become commonplace within the information technology and healthcare fields and are sometimes used interchangeably. In a recent study that interviewed medical and information technology professionals, it was found that "there is no clear, common understanding of a definition, scope, or boundaries of what constitutes as telemedicine" [28]. One of the definitions of Telemedicine or Telecare or Telehealth includes "a data transmission process to collect data from a patient's health status to allow remote controlling and/or managing a patient's health" [24]. mHealth is largely viewed as the delivery and practice of healthcare supported by mobile technologies. Both mHealth and Telemedicine fall under the eHealth umbrella.

The current research articulates the following definition of e-health: "The application of information, communication, computing, and sensing technologies across the entire range of functions and processes constituting the practice and delivery of healthcare services" (adapted from the concepts presented by Eysenbach and Silber). The current definition broadens the scope of e-health to include the primary and secondary value functions of the healthcare systems.

Table1: primary actors in the healthcare system.

\begin{tabular}{|c|l|}
\hline $\begin{array}{c}\text { Particip } \\
\text { ants }\end{array}$ & \multicolumn{1}{c|}{ Description } \\
\hline Patients & $\begin{array}{l}\text { Patients are the primary consumers of the } \\
\text { healthcare industry. Majority of people in } \\
\text { the United States of America (USA) do not } \\
\text { use the services of the healthcare industry } \\
\text { with the average annual doctor visits being } \\
\text { approximately 5.5 (increase from 4.5/year } \\
\text { in the 1960s). 1\% of the total population } \\
\text { (half of which are the elderly segment of } \\
\text { the population) account for 30\% of all } \\
\text { expenses, the top 10\% account for 72\% and } \\
\text { the top 15\% account for approximately } \\
\text { 85\% of the total healthcare expenses [6]. } \\
\text { These statistics indicate the concentration } \\
\text { of healthcare delivery cost among a small } \\
\text { fraction of the total population, many of }\end{array}$ \\
\hline
\end{tabular}

\begin{tabular}{|c|c|}
\hline & $\begin{array}{l}\text { which belong to the elderly segment. Hence } \\
\text { containing healthcare cost implies new and } \\
\text { innovative ways of providing quality care } \\
\text { to the aged population suffering from } \\
\text { chronic diseases. Research also shows that } \\
\text { on average patients only get 10-minutes } \\
\text { face-to-face time with the medical } \\
\text { professionals, e-health can provide an } \\
\text { access to health information to patients. E- } \\
\text { health can help educate patients and } \\
\text { promote improved self-management [8] }\end{array}$ \\
\hline $\begin{array}{l}\text { Medical } \\
\text { Professi } \\
\text { onals - } \\
\text { Physicia } \\
\text { n, } \\
\text { Nurse, } \\
\text { Clinicia } \\
\text { n }\end{array}$ & $\begin{array}{l}\text { Healthcare providers are the } \\
\text { clinicians/hospitalists, nursing staff and the } \\
\text { doctors whose key goal is provide treatment } \\
\text { to patients, manage diseases, avert any } \\
\text { sickness that is preventable and provide } \\
\text { relevant information to the patients } \\
\text { regarding their sickness and towards a } \\
\text { healthy lifestyle. Healthcare services in the } \\
\text { late } 1990 \text { s were provided by approximately } \\
600,000 \text { practicing physicians, 100,000 } \\
\text { dentists, 6600 hospitals, 9000 medical } \\
\text { laboratories, and } 60,000 \text { pharmacies in the } \\
\text { United States [6]. For providers, e-health is } \\
\text { a way to improve efficiency, } \\
\text { communication, and reduction in } \\
\text { administrative costs. }\end{array}$ \\
\hline $\begin{array}{l}\text { Supplier } \\
\text { s - } \\
\text { Pharmac } \\
\text { eutical } \\
\text { Drug } \\
\text { Provider } \\
\text { s, } \\
\text { Medical } \\
\text { Supplier } \\
\text { s etc. }\end{array}$ & $\begin{array}{l}\text { Suppliers service the healthcare sector in } \\
\text { much the same way as suppliers of parts } \\
\text { service the automotive industry. Healthcare } \\
\text { providers and Healthcare vendors provide a } \\
\text { large array of supplies required for the day } \\
\text { to day operation and delivery of healthcare. } \\
\text { The supplies range from bed sheets to } \\
\text { pharmaceutical drugs, from garden } \\
\text { equipment to surgical equipment, and from } \\
\text { pencils to X-ray films. Procuring and } \\
\text { Healthcare supply is a task intensive sector } \\
\text { of the healthcare industry accounting to } \\
\text { approximately } \$ 90 \text { billion in revenue [23]. }\end{array}$ \\
\hline $\begin{array}{l}\text { Payers - } \\
\text { Insuranc } \\
\text { e } \\
\text { Compan } \\
\text { ies } \\
\text { (Public/ } \\
\text { Private), } \\
\text { Direct } \\
\text { Payers }\end{array}$ & $\begin{array}{l}\text { The revenue in the healthcare industry is } \\
\text { generated by the health care payers } \\
\text { comprising of private insurance companies } \\
\text { ( } 33.1 \%) \text {, government insurance ( } 45.4 \%) \\
\text { and direct payers (17.4\%) [6]. When the } \\
\text { insurance companies first came into } \\
\text { existence almost a decade ago, enrollment } \\
\text { was completely voluntary and was based on } \\
\text { the fact that the insurance companies, much } \\
\text { like auto insurance, would cover the large } \\
\text { expenses associated with unexpected } \\
\text { medical bills. The insurer was paid a } \\
\text { premium for underwriting the risk of high } \\
\text { costs. As the population aged and medical } \\
\text { technology advanced, health care costs rose }\end{array}$ \\
\hline
\end{tabular}




\begin{tabular}{|c|c|}
\hline & $\begin{array}{l}\text { sharply and so have the insurance } \\
\text { premiums [3]. For insurance companies, e- } \\
\text { health will be way to further promote } \\
\text { legible, complete documentation and } \\
\text { accurate coding and billing (Healthit.gov). }\end{array}$ \\
\hline $\begin{array}{l}\text { Diagnos } \\
\text { tic } \\
\text { Service } \\
\text { Provider } \\
\text { s } \\
\text { Laborat } \\
\text { ory } \\
\text { Service } \\
\text { Provider } \\
\text { s, } \\
\text { Radiolo } \\
\text { gy } \\
\text { Service } \\
\text { Provider }\end{array}$ & $\begin{array}{l}\text { Diagnostic service providers such as } \\
\text { laboratories, radiologists etc. provide } \\
\text { relevant information to the doctors, nurses, } \\
\text { and other allied medical professionals } \\
\text { regarding the patient. This information aids } \\
\text { medical professionals in making accurate } \\
\text { diagnosis of patient's health status and } \\
\text { providing prescription drugs and/or other } \\
\text { treatment options. The diagnostic service } \\
\text { providers collect required specimen from } \\
\text { the patients, provide tests/imaging results to } \\
\text { the medical professionals, and obtain } \\
\text { payments for their services from the } \\
\text { insurance companies or the patients. The } \\
\text { diagnostic service providers }\end{array}$ \\
\hline
\end{tabular}

\section{Enabling Technologies}

E-health is enabled by integrated applications embedded in the environment. The technological innovation/advancement enabling the multitude of applications and services fall into three distinct classes of technologies: ubiquitous computing, ubiquitous communication, and ubiquitous biomedical sensing (figure 2).

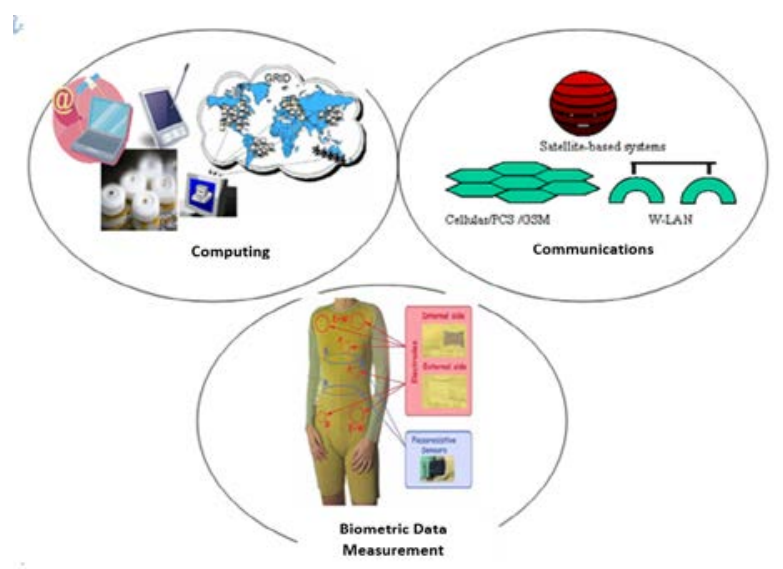

. Figure 2: Technologies Enabling E-Health

A. Computing seeks to bridge the gap between the virtual and physical world by incorporating computing power (microprocessors) and sensing (sensors) into anything, including not only conventional computers, personal digital assistants (PDAs), mobile phones, printers, etc., but also everyday objects like white goods, toys, plates, cups, glasses, houses, furniture, or even paint ("smart dust") [14].
Over the past years, emerging computer technologies have drawn enormous attention as they often yield new and innovative use in work as well as in leisure. We are currently on the move away from traditional desktop-based computer technologies towards ubiquitous computing environments that will potentially enfold us in almost all of everyday situation and activity. A relatively recent advancement in computing is "Grid Computing" which has taken the distributed computing paradigm to a much higher level. Grid technologies create dynamic and secure environments for computing and storing resources thereby allowing doctors from across the globe to not only access patient's data but run complex simulations and virtual surgical procedures [7]. A large amount of computing resource is available to a typical hospital, only $5-10 \%$ of which is used at a given point in time. Mobile grid computing can couple all the idle computational resources, the attached benefits translate into an improvement of the quality of the data, a decrease in development costs for integrating data and an efficient sharing of electronic patient-related information [12]. Ubiquitous computing systems can potentially influence the change in workflow of the health care management. Information technology may contribute to improve performance, reduction of errors made in treatment of patients, reduction of economic costs, etc. Research conducted by Jesper Kjeldskov [18] has evaluated the performance of IBM's EPR system IPJ 2.3. The results show that workers in the healthcare domain can benefit from ubiquitous computing environments and that ubiquitous computer environment in the healthcare domain may be improved through mobile and context aware points of access. However, it also suggests the more improvement has to done as technological innovation is never ending process.

B. Communication is enabled by mobile computing which allows continuous access to data and communication power. Recent years has seen a trend in increasing processing power and communication bandwidth along with the corresponding decrease in the cost of processing and communication, with respect to both hardware and software and power consumption [19][36][16]. This trend has made it possible to integrate processing power and communication capacity to more simple and inexpensive devices and objects than was feasible before. With 350 million mobile devices worldwide and 80 million in United States itself it is evident that the PDAs and mobile devices are slowly becoming an integral part of our lives [35]. These mobile devices offer a mobile wireless platform for running healthcare applications, a user interface and data logging potential for health sensors and monitoring devices, and a gateway to 
connect local devices collecting health related information to global services such as hospital databases [15].

Research shows that mobile apps are viewed as a positive tool in monitoring the post-operative of recovery of patients at home. The mobile app is very beneficial in expediting discharge and it also helps in detecting complications. Studies show that such mobile apps at home are feasible to patients and they are approved by patients and surgeons. Surgeons reported that the app makes it easier for them to monitor patients outside of hospital, and it has the ability to improve time efficiency.

Many studies have been done to see the effectiveness of mobile phones for weight loss [13]. The authors used mobile-phone apps or web-based programs that could be accessed from mobile apps. These technologies allowed them to see the weight-loss intervention or for evaluation the progress for use and their acceptance among users. The relationship between weight loss and program use was proportional. The studies proved that the programs benefitted those who participated. Mobile health (mhealth) applications have been looked as a positive tool to improve performance of health workers and health systems. A study done among midwives, and health extension workers, in Ethiopia, found that the use of electronic forms of smartphones is very beneficial in day-to-day maternal health care services delivery [21].

In 2012, the US Food and Drug Administration reported that around 1,828 health and fitness and 14,558 medical apps are available. Use of health apps have increased over the years. There are several apps that are currently promoted in the Health-e-Apps page of the eHealth Strategy website. The category includes apps for nutrition and exercise tracking such as "My Fitness Pal”, heart rate tracking app "Health Rate”, sleep tracker "Sleep Tome, and mood tracker "Mood Panda”.

Mobile technology is increasing day by day. Even in low and middle-income countries mobile access is greater than access to computers. Mobile communications and advancement of smartphones made health care delivery very handy. Hospital workers are highly mobile during their working day many technologies supports in providing health care. These technologies offer powerful means for restructuring many health service processes, and there currently are increasing arrays of communication channels, media, and devices from which communication services can be constructed.
Recent advances in technology of wireless sensor networks and low powered integrated circuits enable the design of low cost intelligent nodes. These nodes are capable of sensing, processing, and communicating vital signs and can be integrated in wireless body networks. These networks promise health monitoring with almost real-time updates of medical records via the Internet. Later, as more research is done, a way will be paved to use wearable technology that uses WBAN and SOA services for time-to-time updates to health care management systems [33]. Most of the mobile networks and wireless sensor networks use public networks so there is a high risk of new security and privacy challenges. As most of the data is stored in cloud nowadays, patient data is exposed to various security breaches. Moreover, patient data stored on cloud servers are also exposed to malicious attacks. So many security based architecture is more crucial to provide security. However, discussing security in Ehealth would broaden the scope of this paper as we try to focus on proposing a framework for effective Ehealth delivery.

C. Sensing via wearable biomedical sensors [30], smart biomedical clothing [4], and other monitoring devices has enabled the collection and analysis of physiological patient data anytime, anywhere without any location dependencies [22]. Computer-tailored physical activity (PA) interventions that are delivered through the use of internet have been proven to be a promising and appealing method to promote physical activity. Computer-tailored, pedometer-based physical activity intervention has been an effective method to promote physical activity in the at-risk population. In order to monitor people living alone Ultra-wideband (UWB) radio sensor network device has been proposed by Sachs and Herrmann [27]. This network is based on M-sequence technology and it can be installed in many living spaces. The interaction between user and device is very minimal and the radar sensor is based on motion detection and tacking. Sensing devices have been used to help patients improve their health needs. Such devices are not as reliable as seeing a professional. Many patients don't trust these devices as they prefer to see a professional. In order to increase the reliability of these devices there needs to be further investigation, which will help provide more features to gain patient's trust.

\section{The Value Proposition of E-health}

Figure 3 presents the value proposition [26] of e-health to the primary and secondary value processes of the healthcare systems (adapted from Porter's Framework). 


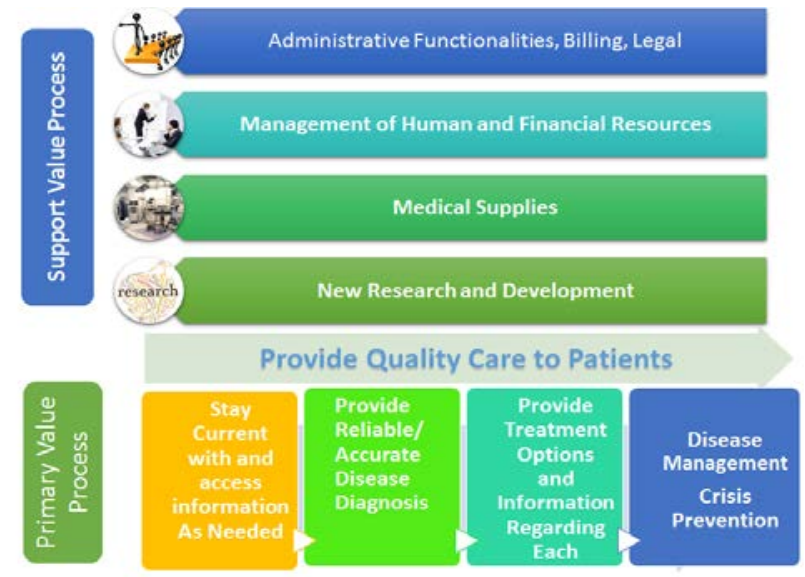

Figure 3: The Value Proposition of E-Health

4.1. Primary Value Processes (PVP) includes the core functionalities of the healthcare sector, i.e., accurate reliable disease diagnosis, provision of appropriate treatment, and prevention of crisis via disease management. The key stakeholders associated with PVPs include the healthcare professionals such as doctors, nurses, laboratory specialists, radiologists etc. and healthcare consumers i.e., patients. Insurance companies also play a critical role in countries where the payment to the healthcare professionals for their services comes from insurance companies. Other parties that could be affected by adaptation of e-heath are next of kin and informal caregivers. (f)

A. Pre-Diagnosis (PD) refers to the process of "knowing what is known". The primary actors in this process are the healthcare professionals who have the responsibility to be abreast with relevant medical information such that they are capable of providing best possible services to the patient at a given point in time. The traditional model of healthcare delivery and practice provides a very myopic view of the advancement in healthcare research and limits the ability of physicians to stay abreast with latest advances in the field of healthcare.

E-health can also be used to conduct online consultations with patients and medical specialists [20]. Web based tools can be very beneficial in early detection and prevention of diseases. A tool that proved to be helpful is the Heart Age Tool which is a web-based self-assessment tool that is very useful to interact with people who are at risk of developing diseases such as cardiovascular disease, cholesterol, and blood pressure [1]. A European survey reports that only $10 \%$ of general practitioners use the online consultation system and less than $16 \%$ of general practitioners consult with other medical specialists online [10].
Through E-health, healthcare providers have access to other resources, such as consultations from other healthcare professionals and recommendations made by medical teams. There are many online resources that help physicians gain more knowledge to better their healthcare delivery. Such resources include blogs, YouTube channels, smartphone apps, and articles. AMA Insurance Agency Post Scripts Blog is a great source for physicians to get information about current issues faced by physicians on a daily basis such as practice management, financial/insurance security planning information and insights on physician insurance needs. De Leo et.al conducted a study to see the Internet resource that physicians preferred to consult. This study concluded that physicians often use a targeted site rather than utilizing search engines such as Google or Yahoo. Of the targeted site types, the study reveals 1) most physicians indicate they use edited/secondary data sources as their primary medical information data retrieving, 2) about one quarter of the physicians surveyed indicated research databases which provide access to medical journal publications, 3) a minority of physicians use sites dedicated to their specialized area, and 4) a small percentage use medical web site portals [9].

Both clinical and administrative decision helps doctors to provide better medical care. Where clinical decision making leads to diagnostic and managing treatment plans and administrative decision leads to a list of requirements to make administrative decisions. For example, clinical decision support systems (CDSS) are clinical consultation systems that use one or more knowledge bases to assist clinicians making optimal decisions. These systems aid patient management and consultation through analysis of patient-specific information. The knowledge management cycle involves all the processes that help to gather all the knowledge from different sources by integrating all the functions for effective health care systems.

Advancement in mobile applications also paved a way to provide better health care by using applications. Many such tools have been developed focusing on health care. Some of the applications include read apps that give up-to-date news of popular journals, doctor's ability to search for any issue within the reach of fingertips, some situations where physicians may not understand the patient's disease. Sharing diagnostic results with other people in the same field can help a physician understand the main problem more easily. Most of the applications are knowledge-centric and some of the applications are service-oriented. 
B. Accurate Reliable Diagnosis and Treatment $\underline{(\mathbf{D} / \mathbf{T})}$ refers to the process of healthcare professionals using relevant "pre-diagnosis" knowledge to providing accurate diagnosis and appropriate treatment to the patients. The two primary stakeholders in this stage include the healthcare professionals and patients. Accurate diagnosis is directly related to the healthcare professionals' prior knowledge and precise patient information pertaining to medications, test results, etc. In the traditional healthcare environment healthcare professionals are handicapped in gathering pertinent patient information due to reliance on error-prone paper records and delays in obtaining correct information. Proper treatment of the diagnosed conditions is also directly proportional to the healthcare professionals' knowledge base regarding diseases and corresponding treatments. Treatments can include any combination of medications, surgeries, diet management etc. The best treatment options could potentially vary from case to case. E-Health empowers doctors in making accurate disease diagnosis and empowers patients in taking control of their diseases, obtaining second opinions without any geographical constraints, etc. [25]. E-health can also play a role in reducing the travel time for necessary medical reports and other documentation such as labs and scans. Ehealth can play an important role when patients decide to seek treatment outside of their hometown, be it out of state or out of country. E-health leads to safe information transfer among health professionals.

Telemedicine is a cost-effective way of providing consultation without having face-to-face contact with healthcare professionals. Telemedicine increases benefits for patients and allows quick exchange of information and techniques between healthcare professionals. Telemedicine is a beneficial tool for patients who are trying to seek second opinion regarding their diagnosis. In order to achieve a better quality of life some patients need a multi-specialty diagnostic or therapeutic medical or surgical approach. Telemedicine proves to be a very helpful tool in the diagnosing process. Tele-health applications and selfmanagement have a positive impact on the healthcare process outcomes. Empowering chronically ill patients has proven to improve health outcomes and is cost effective [37].

One of the major obstacles in treatment is the patient's inability to understand the actual problem. To avoid such issues, recent applications are attempting to use 3-D animations to simulate the actual disease, enabling a patient to understand the status of his situation and motivate him to comply with the prescribed treatment. Physicians are adopting smart phones into their workflow and healthcare leads the way in proliferating new, innovative apps. From diagnostics to practice management, healthcare technology is giving digital doctors the chance to make their workflow more productive and efficient. Many companies providing web based services for physicians to get in touch with patients without and geographic barriers.

A downfall to this approach is that many patients are not specialized users or consumers of provider health information technology. Many times patients prefer face-to-face interaction rather than technology. E-health does not allow healthcare professionals to provide emotional support towards their patients and in many circumstances patients are in need of emotional connection with their healthcare professional. There is a new trend that allows healthcare professional to provide behavioral needs toward their patients through the Internet. One approach is called web message system that uses secure messaging between physician and patient. This allows healthcare professionals to conduct therapy with more person at a time. Limitations regarding Internet-based therapy include that not all patients can be reached due to computer illiteracy and the lack of face-to-face interaction with the therapist. Another downfall of this approach is that it limits the empathy that a healthcare professional needs to provide towards patients. It also limits their ability to handle patients as unique. Many times healthcare professionals fail to recognize issues that their patient is experiencing. There are additional demands as well when talking about e-health. Those demands are of development and finding new ways to reach to the population. Additionally, there is a lack of resources when trying to reach audience for e-health. Changing the perspective of people is also very difficult task when talking about e-health.

C. Post-Diagnosis/Treatment Disease Management and Crisis Prevention (DM/CP) refers to the process that focuses specifically on disease management and prevention of crisis. The core of this process lies in ensuring that patients understand the consequences/risks associated with the disease and the benefits/probable side-effects of the corresponding treatment, and that patients comply with the prescribed treatments. Disease management based on pervasive monitoring of patients to ensure compliance and to detect anomalies before they snowball into a crisis can translate into reduction in healthcare costs associated with avoidable hospitalizations and an improved lifestyle for patients outside of the hospital. Patients are able to manage their health in an efficient way. Patients do not have to rely on appointments; instead many of their questions will be answered through an e-health 
system. Healthcare professionals can monitor patients' health as well.

Caregivers and next-of-kin play a big part when it comes to family members for whom it is difficult to care for them. After discharge, caregivers play a big part in patients' life. Next-of-kin and caregivers play a big part in medication management, monitoring vital signs, falls prevention, and ensuring regular and healthy nutrition. E-health allows caregivers to connect directly with peers and health professionals. Some argue that user/patient control, privacy, data protection, and consent are big hurdles in adapting e-health. The issue of consent becomes very important when talking about e-monitoring devices. Another example of ehealth is the use of e-prescription and doctor-patient email interaction. General practitioners only make limited use of both e-prescription and doctor patient email interaction. Telehealth can be defined as a delivery of health-related services through telecommunication technologies. Telehealth is another way of reducing the need of patients stay at the hospital and it helps increase the safety of living independently, yet according to one survey in Europe only $8 \%$ of hospitals share information electronically [10]. E-Health involves a new and different form of communication between physicians and patients. From the standpoint of ethics, this interaction comes with challenges and threats. Such threats and challenges to ethical issues include online professional practice, privacy, equity issues, and informed consent. Controlling how much information patients should receive is another barrier to e-health. Too much information could be harmful in many situations. Test results that patients can view without explanation from the physician can be harmful in many ways. There is not much research that shows what will happen when patients are provided with full access to their own records. Research shows that ensuring that patients have computer hardware and Internet connection are not the only factors to ensure patient access. Other than physical accessibility it is very important to make sure that users have the ability to locater personally relevant resources. Technology literacy, usability, and technical accessibility are also very important when talking about patient accessibility to e-health. Extant research suggests that there is much to be addressed in methodology, implementation, and evaluation process.

4.2. Secondary Value Processes (SVPs) include all the functions that support the PVPs such as: billing to insurance companies/patients for service fees, legal department to ensure services are meeting the minimal standards, medical supplies procurement of desired quality at reasonable cost for day-day functioning of healthcare sector, research and innovation to find cure to existing ailments, and increasing the knowledge base. E-health reduces unnecessary duplication of paperwork.

E-health has been a successful resource when it comes to insurance companies. Medicaid and Medicare services have their own online portals to check the eligibility of patients. Portals allow the billing department to see the enrollment information and benefits of qualifies patients. Some private insurance companies also have portals that allow hospital staff to see patients' eligibility status. These portals make it easier for the billing department, enabling patients to receive their healthcare needs in a more-timely fashion.

There are many medical supply online companies where healthcare providers order medical supplies 24/7. One prominent company is the Henry Schein Medical; the company provides access to over 500,000 products. The website also provides a way to create a customized shopping list, and perform advanced product searches. Another web page that provides access to medical supplies is Moore Medical. This website allows physicians to access Rx \& OTC Pharmaceutical products, branded name supplies, product variety and online or over the phone support. Overall technology has made ordering easy for medical professionals to order supplies online. E-script is a way for medical professionals to submit patient prescriptions to pharmacies. Express Scripts allows physicians and patients to submit prescriptions online. This website also allows mobile access for patients so they can manage their prescription anytime and anywhere. The benefits of E-scripts include 1) improved patient safety, reducing transcription errors during dispensing, 2) improved workflow of pharmacy and health care supply chain management, 3) doctors' ability to access the history of the medicine dispensing. One recent project called MedView helps to gather prescription information from different sources that can be used to understand the trends in medical prescription or research. To improve research and disease understanding, many companies are investing in systems to store genomic information, thereby providing data to research efforts such as Genetix Ltd.

\section{Conclusion}

Over centuries the praxis of healthcare has evolved to address socio-economic pressures and the needs of the time. Innovations such as vaccinations and antibiotics have reduced mortality and enhanced the quality of lives of millions across the globe. At the turn of the 21st century, healthcare sector globally is facing immense pressure due to spiraling healthcare costs and 
a parallel increase in aging population thereby necessitating a need for the next wave of evolution in the praxis of healthcare. This research explores the paradigm of e-health and makes the following contributions: 1) analysis of the current healthcare environment and identification of the potential opportunities and challenges, 2) description of e-health and classification of the enabling technologies, 3) conceptual framework of e-health's value proposition depicting the primary and secondary value processes of the healthcare sector, 4) a comparative analysis of ehealth, and 5) outlines the corresponding research issues and challenges.

Although E-health offers an array of opportunities for cost reduction and improved quality of care delivery and practice, the outcomes and the associated savings haven't been demonstrated [2, 38]. Some argue that the potential of e-health can be realized only if the patient is kept at the epicenter and the barriers associated with socio-cultural/behavioral, organizational, financial, political, and technical are addressed with the objective to empower patients [2]. At the organizational level, the biggest issues are situated in assimilating the changed processes and assessing the intended and unintended consequences of the changes. Availability of appropriate technical and financial resources such as computing power, telecommunication technology, Internet hosts/service providers (ISPs), high bandwidth and broadband access, and electricity are key to the wide scale diffusion of e-health Even if the technical and financial resources are available, the litmus test of e-health's success would lie in the adoption of its applications and services by two critical user groups; patients and providers [2]. Prior research suggests that few key barriers to widespread adoption include lack of interoperability, security concerns, associated costs, [2]. However, the complexity and high stakes associated with e-health makes it a rich problem space that calls for further research to extend or refute existing research. As cloud based solutions are increasing in all levels of industry, health care management tools should be able to integrate easily with other applications to provide interoperable solutions upon which lies challenging goals ahead. A detailed discussion of each process in the value proposition model based on technical, socio-cultural, behavioral, financial, political, and security challenges is another key domain that calls for future research. An in-depth discussion of the various healthcare structures and systems and an evaluation of the variability in outcomes of e-health applications across those areas is also relevant and important subjects to be considered for future research. Although, e-health is still in its infancy, the opportunities and challenges are vast and the realization process has merely just begun.

\section{References}

1. American Hospital Association, "Health Leaders Fact file: Rising Cost Comes as No Surprise” July 2002

2. Anderson, G.F. et. al., Health Care Spending And Use Of Information Technology In OECD Countries, Health Affairs 25, no.3 (2006):819-831

3. Bohmer, R., Note on Managed Care, September $29^{\text {th }} 1999$.

4. Cardionet: http://cardionet.com/

5. Chiasson, M., Davidson, E., et al., Strangers in a Strange Land: Can IS Meet the Challenges and Opportunities of Research in Healthcare, Proceedings of the Tenth Americas Conference in Information Systems (AMCIS) (2004).

6. Coughlin, Peter. J., Rukstad, M. J., Johnston, C., Case Study, Harvard Business Online, May $29^{\text {th }}$ 2001.

7. Covington, M. J., Securing Context-Aware applications using environment roles. In Symp. On Access Control Model and Technology, May 2000

8. Davis, D.A. et. al., "Accuracy of Physician Selfassessment Compared With Observed Measures of Competence: A Systematic Review”, JAMA.

9. De Leo, G., et al. "Websites most frequently used by physician for gathering medical information." AMIA Annual Symposium Proceedings. Vol. 2006. American Medical Informatics Association, 2006.

10. European Commission. "eHealth in the EU: What's the Diagnosis?" press release, http://europa.eu/rapid/press-release_IP-14302_en.htm Accessed on 09.03.2016.

11. Eysenbach G, Yihune G, Lampe K, Cross P, Brickley D. Quality management, certification and rating of health information on the Net with MedCERTAIN: using a medPICS/RDF/XML metadata structure for implementing eHealth ethics and creating trust globallye1. J Med Internet Res 2000 Jun;2(2 Suppl):2e1. [PMID: 11720933]

12. Foster, I. et al. The Anatomy of a Grid: Enabling Scalable Virtual Organizations. International Journal of Supercomputer Applications. 2001. Vol. 15, Issue 3.

13. Free, C. et al. "The Effectiveness of Mobile-Health Technology-Based Health Behaviour Change or Disease Management Interventions for Health Care Consumers: A Systematic Review." PLOS Medicine 10.1 (2013). 
14. Gator Tech Smart House, https://www.cise.ufl.edu/ helal/gatortech/index2.h tml

15. Gaynor, M., Moulton, S.L., Welsh, M., LaCombe, E., Rowan, A. and Wynne, J. Integrating wireless sensor networks with the grid. IEEE Internet Computing, 8 (4), 2004, 32-39.

16. Goldberg, Steve et al. $21^{\text {st }}$ Century Healthcare The Wireless Panacea. Proceedings of the $36^{\text {th }}$ Hawaii International Conference on Systems Sciences (HICSS 2003).

17. Institute of Medicine. Preventing Medication Errors: Quality Chasm Series. Washington DC: Institute of Medicine; 2006.

18. Kjeldskov, J. \& Skov, M.B. Pers Ubiquit Comput (2007) 11: 549. doi:10.1007/s00779-006-0112-5

19. Korhonen, I. et al. Guest Editorial Introduction to the Special Section on Pervasive Healthcare, IEEE Transactions on Information Technology in Biomedicine, Vol. 8, No. 3, September 2004

20. LifeSync - www.wirelessecg.com, 2005

21. Little, A., et al. "Meeting Community Health Worker Needs for Maternal Health Care Service Delivery Using Appropriate Mobile Technologies in Ethiopia." PLOS ONE 8.10 (2013).

22. Lymberis, A. (2003) Smart Wearables for Remote Health Monitoring, from Prevention to Rehabilitation: Current R\&D, Future challenges, Proceedings of 4th International IEEE EMBS Special Topic Conference on Information Technology Applications in Biomedicine, 272 275.

23. McGee, M.K. E-Health on the Horizon, Informationweek.com, May $17^{\text {th }} 2004$.

24. Mercuri, R.T. (2004). The HIPAA-potamus in Health Care Data Security. Communications Of The ACM, 47(7), 25-28. doi:10.1145/1005817.1005840

25. My Consult Program of E-Cleveland Clinic http://www.eclevelandclinic.org/displayContent.js p? productId=nutrition \&document $=$ document/que $\underline{\text { stions }}$

26. Porter, Michael E. (1985). Competitive Advantage: Creating and Sustaining Superior Performance
27. Sachs, J. and Herrmann, R. "M-sequence-based ultra-wideband sensor network for vitality monitoring of elders at home." IET Radar, Sonar \& Navigation 9.2 (2015): 125-137.

28. Showell, C., \& Nøhr, C. (2012). How should we define eHealth, and does the definition matter?. Studies in Health Technology and Informatics, 180881-884.

29. Silber, D., “The Case for eHealth", European Commissions $1^{\text {st }}$ High Level Conference on eHealth, May 22-23, 2003

30. Smart Shirt: http://www.smartshirt.gatech.edu

31. Sneha, S. and Varshney, U. Ubiquitous Healthcare: A New Frontier in E-Health, In Proc. of the twelfth Americas Conference on Information Systems, Acapulco, Mexico AMCIS (2006).

32. Sneha, S. and Varshney, U., Enabling Ubiquitous Patient Monitoring: Model, Decision Protocols, Opportunities and Challenges, Decision Support Systems, January, 2009

33. Suzuki, T. and Doi, M. (2001) LifeMinder: An Evidence-Based Wearable Healthcare Assistant, Proceedings of the ACM CHI Conference

34. Tablado, A., Illarramendi, A., Bermudez, J., and Goni, A., Intelligent Monitoring of Elderly People; In Proc. $4^{\text {th }}$ Annual IEEE Conf. On Information Technology Applications in Biomedicine UK (2003)

35. Varshney, U. et al. Mobile Commerce: A New Frontier. IEEE Computer October 2000.

36. Varshney, U. Pervasive Healthcare: Applications, Challenges and Wireless Solutions. Communications of the Association of Information Systems. Vol.16, 2005

37. Wagner, Edward H., et al. "Improving chronic illness care: translating evidence into action." Health affairs 20.6 (2001): 64-78.

38. Walker, J. "Electronic Medical Records and Health Care Transformation,” Health Affairs 24, no. 5 (2005):1118-1120. 